\title{
ENERGY PERFORMANCE OF BUILDINGS
}

\section{ABSTRACT}

Daniel Hlubeň, L'ubomír Beňa

The paper entitled "Energy performance of buildings" deals with the new standard prEN 15 193. The main goal of this standard is to assess energy consumption of lighting in a building and minimize energy consumption of lighting.

\section{INTRODUCTION}

According to the aim of European Union to improve efficiency of electric energy consumption, several standards were published during last year. [1]

The main goal of these standards is to assess energy consumption. Buildings assessed according to this methodology are divided into several groups $(A, B, \ldots, G)$, according to the efficiency of the whole building. This assessment includes several fields and the lighting is one of these fields.

This article describes briefly prepared standard for energy performance of buildings - "Energy requirements for lightning".

\section{ENERGY REQUIREMENTS FOR LIGHTING}

The main goal of this standard is to establish conventions and procedures for the estimation of energy requirements of lighting in buildings and to give a methodology for a numeric indicator of energy performance of building. [2]

At the beginning, it is necessary to write, that there are several methods, how to assess energy performance:

- Quick method

- Comprehensive method

- Measurement of lighting circuit

Methods division can be seen on figure 1 .

\subsection{Quick method}

Quick method uses for the LENI index calculation the following formula

$$
\mathrm{LENI}=\left\{F_{\mathrm{C}} \times P_{\mathrm{N}} / 1000 \times\left[\left(t \mathrm{DX} F \mathrm{D} \times F_{\mathrm{O}}\right)+\left(t \mathrm{~N} \times F_{\mathrm{O}}\right)\right]\right\}+1+\left\{5 / t_{\mathrm{y}} \times\left[t_{\mathrm{y}}-(t \mathrm{D}+t \mathrm{~N})\right]\right\}\left[\mathrm{kWh} /\left(\mathrm{m}^{2} \times \text { year }\right)\right]
$$

$\mathrm{P}_{\mathrm{N}}$ Total installed lighting power in the room or zone

$\mathrm{F}_{\mathrm{c}}$ Constant illuminance factor

$t_{D} \quad$ Daylight time usage $[\mathrm{h}]$

$t_{N} \quad$ Non-daylight time usage [h]

$\mathrm{t}_{\mathrm{y}} \quad$ Standard year time

$F_{O}$ Occupancy dependency factor

$\mathrm{F}_{\mathrm{D}}$ Daylight dependency factor

It is necessary to emphasize that this method is for fast calculation only and LENI index is usually higher. This calculation has an informative character. 


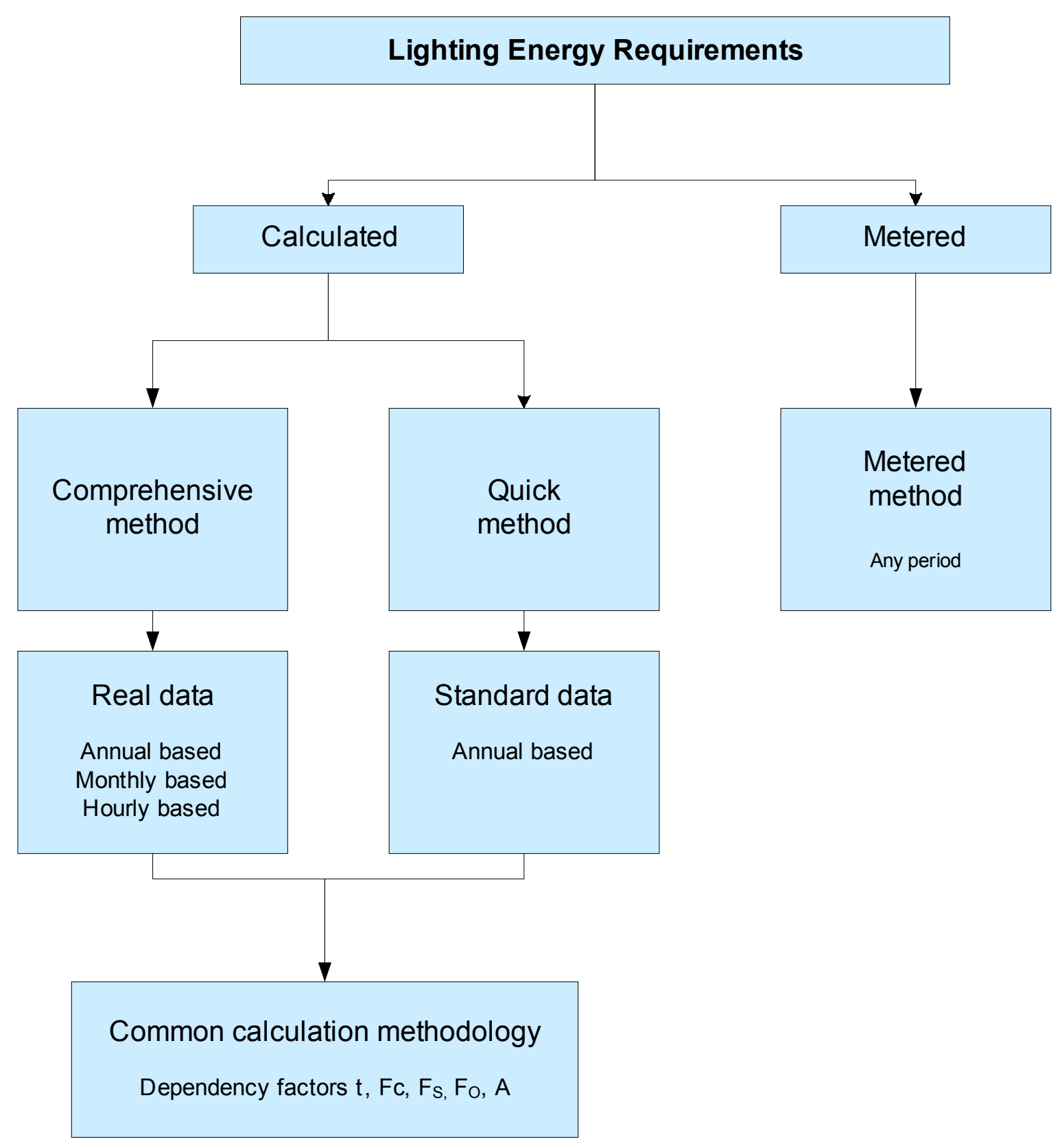

Figure 1 - Flow chart illustrating alternative routes to determine energy use

\subsection{Comprehensive method}

This method is more complicated. It is out of range of this article to describe this method into depth, therefore there are showed only some factors, which are taken into account

- Daylight area (a zone receiving daylight) 


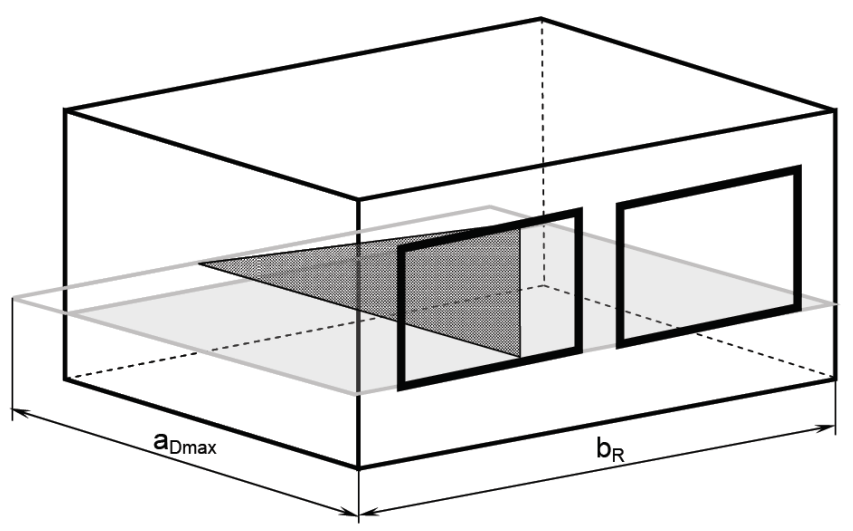

Figure 2 - Daylight area $\left(a_{D \max } \times b_{R}\right)$

- Rooflights (e.g. glass pyramid, glass roof window, glass ridge, polycarbonate ridge, polycarbonate pyramid, polycarbonate dome)

\section{- Obstructions}

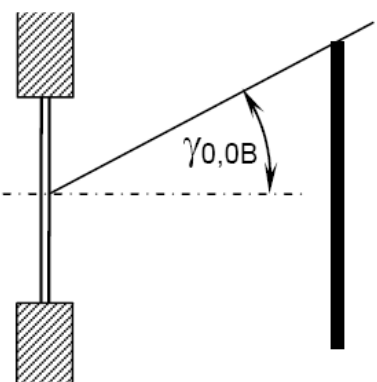

Figure 3 - Obstruction caused by e.g. another building

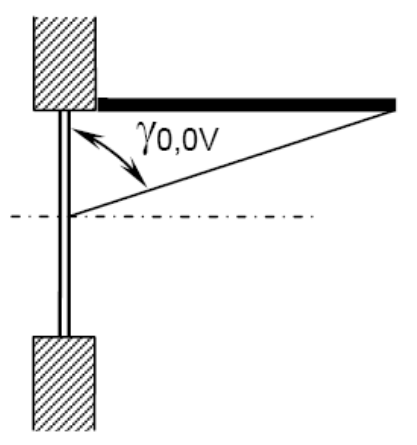

Figure 4 - Overhang

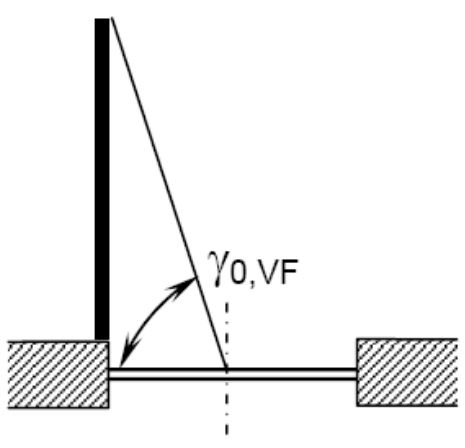

Figure 5 - Vertical fin 


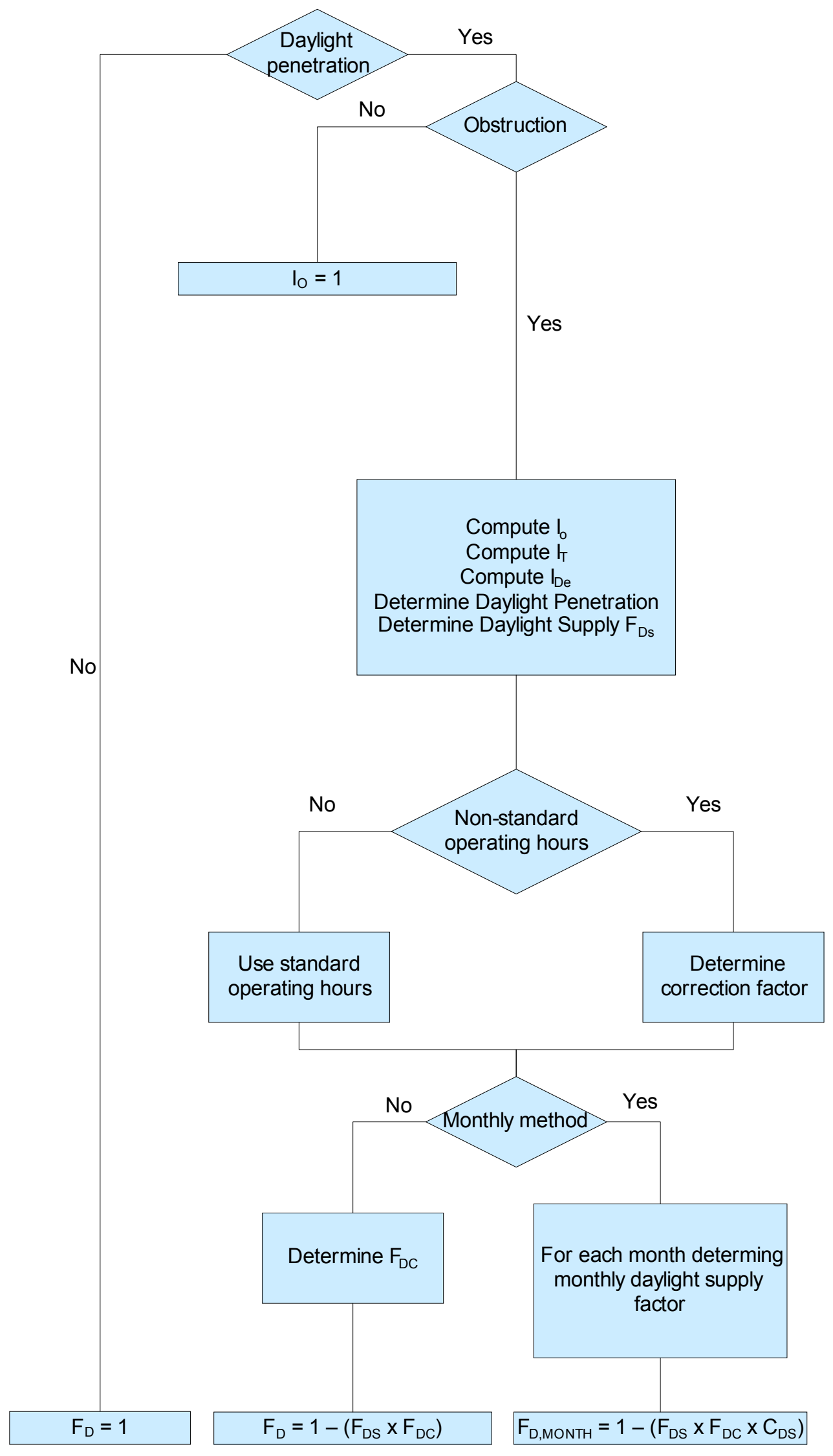

Figure 6 - Flow chart illustrating the determination of the daylight dependency factor $F_{D, N}$ in a zone. 


\subsection{Measurement}

The lighting consumption shall be separately measured using one of the following methods:

a) $\mathrm{kWh}$ meters on dedicated lighting circuits in the electrical distribution;

b) local power meters coupled to or integrated in the lighting controllers of a lighting management system;

c) a lighting management system that can calculate the local consumed energy and make this information available to a building management system (BMS);

d) a lighting management system that can calculate the consumed energy per building section and make this information available in an exportable format, e.g. a spread sheet format;

e) a lighting management system that logs the hours run, the proportionality (dimming level) and relates this to its internal data base on installed load.

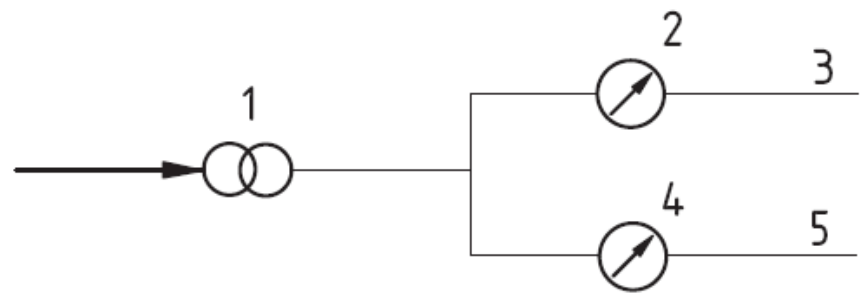

Figure 7 - Measurement

Then we have, that

$$
W=W_{\text {light metered }}[\mathrm{kWh} / \text { year }]
$$

\section{LENI CALCULATION}

Lighting Energy Numeric Indicator for the building

$$
L E N I=W / A\left[\mathrm{kWh} /\left(\mathrm{m}^{2} \times \text { year }\right)\right]
$$

But it is necessary to emphasize, that this LENI index is valid, if standards like EN $12464-1$ are fulfilled. This indicator does not take into the account different rooms (area) and their lighting.

Therefore it is necessary to define new variables, which will take it into account, and the resulting index will be e.g.

$$
W_{E}=\frac{W}{\sum E_{m} \cdot A}
$$

But real (measured) illumination could be lower than required illumination. The following formula takes it into the account:

$$
\begin{gathered}
W_{E^{\prime}}=\frac{W}{\sum_{i=1}^{n} E_{m, i} \cdot A_{i} \cdot \eta_{o, i}}=\frac{W}{\sum_{i=1}^{n} E_{m e s, i} \cdot A_{i}},\left[\frac{\mathrm{W}}{\mathrm{m}^{2} .1 \mathrm{x}}, \mathrm{W}, \mathrm{m}^{2}, \mathrm{~lx}\right] \\
\eta_{o, i}=\frac{E_{m e s, i}}{E_{m, i}},[-, 1 \mathrm{x}, \mathrm{lx}]
\end{gathered}
$$


Where

$\mathrm{E}_{\mathrm{m}, \mathrm{i}} \quad$ required (maintained) illumination for the room [1x]

$\mathrm{E}_{\mathrm{mes}, \mathrm{i}} \quad$ measured illumination [1x]

$\eta_{o, i} \quad$ factor taking into the account requirements of the standard EN $12464-1$

A $\quad$ area $\left[\mathrm{m}^{2}\right]$

W lighting consumption

And finally, according to this factor it is possible to suggest energy saving measures.

\section{CONCLUSION}

This article briefly described methods of the LENI index calculation, but at the end of this article authors have dealt with problem of lighting efficiency calculation. This type of calculation is not taken into account and it will be necessary to add similar factor and classification into the standard.

\section{REFERENCES}

[1] DIRECTIVE 2006/32/EC OF THE EUROPEAN PARLIAMENT AND OF THE COUNCIL of 5 April 2006 on energy end-use efficiency and energy services and repealing Council Directive 93/76/EEC

[2] PrEN 15193: Energy performance of buildings — Energy requirements for lighting

[3] EN 12464-1, Light and Lighting - lighting of workplaces - Part 1: Indoor work places

\section{Author address:}

Ing. Daniel Hlubeň

Department of Electric Power Engineering

Technical University of Košice

Mäsiarska 74

04001 Košice, Slovak Republic

E-mail: daniel.hluben@tuke.sk

Tel: +421 / 55 / 6023559

Fax: +421 / 55 / 6023552

Ing. L'ubomír Beňa, PhD.

Department of Electric Power Engineering

Technical University of Košice

Mäsiarska 74

04001 Košice, Slovak Republic

E-mail: lubomir.bena@tuke.sk

Tel: +421 / 55 / 6023555

Fax: +421 / 55 / 6023552 